\title{
Establishing new microbial cell factories for sustainable bioprocesses
}

\author{
Workman, Mhairi; Holt, Philippe; Liu, Xiaoying
}

Published in:

New Biotechnology

Link to article, DOI:

10.1016/j.nbt.2012.08.211

Publication date:

2012

Document Version

Publisher's PDF, also known as Version of record

Link back to DTU Orbit

Citation (APA):

Workman, M., Holt, P., \& Liu, X. (2012). Establishing new microbial cell factories for sustainable bioprocesses. New Biotechnology, 29S, S75. https://doi.org/10.1016/j.nbt.2012.08.211

\section{General rights}

Copyright and moral rights for the publications made accessible in the public portal are retained by the authors and/or other copyright owners and it is a condition of accessing publications that users recognise and abide by the legal requirements associated with these rights.

- Users may download and print one copy of any publication from the public portal for the purpose of private study or research.

- You may not further distribute the material or use it for any profit-making activity or commercial gain

- You may freely distribute the URL identifying the publication in the public portal

If you believe that this document breaches copyright please contact us providing details, and we will remove access to the work immediately and investigate your claim. 
tor and transporter (transceptors) for amino acids and previous studies have shown that the availability of amino acids for the cell influences diacetyl production. We verified the transcriptome data by immunoblot analysis as Gap1p is known to have strong posttranslational regulation. We proposed the hypothesis that there is a positive correlation between amounts of Gap1pand diacetyl levels. To verify this we analysed diacetyl production under varying Gap1p levels. Diacetyl levels were examined in $\Delta g a p 1$ and in Gap1p overexpression strains of $S$. cerevisiae and compared to the wild type. Our results indicate that influencing Gap1p levels indeed leads to changes in diacetyl levels. We also show a positive correlation between Gap1p expression level and diacetyl levels under brewing conditions using industrial yeast strains. Our results could help towards developing a novel approach to influence diacetyl levels and thus reducing time needed for beer maturation.

Keywords: Beer fermentation; Diacetyl; Transcriptome data; General amino-acid permease; Protein overexpression

http://dx.doi.org/10.1016/j.nbt.2012.08.208

Poster 1.4.05

\section{Scale up of industrial enzyme production}

Rogier Meulenberg

DSM Biotechnology Center, Delft, The Netherlands

Industrial fermentation $\mathrm{R} \& \mathrm{D}$ projects commonly start with laboratory scale strain testing and/or fermentation process development, later followed by transfer of selected strains and optimized fermentation protocols to production facilities. For important fermentation products, business demands are shifting from maximized productivity to increased speed of successful scaling up; time consuming iterations between the scales are no longer tolerated.

One approach in preventing major mishaps in scaling up is proper testing of the sensitivity of key performance indicators of the fermentation process to the differences that are anticipated between the scales. Thus, good scale down models do not only have value in studying scale up effects, but also in business risk reduction.

This contribution presents some experience gained in industrial R\&D practice on (absence of) scale up effects of various fermentation parameters on microbial enzyme production. The results lead to suggested improvements of the design of representative laboratory scale fermentation experiments.

http://dx.doi.org/10.1016/j.nbt.2012.08.209

\section{Poster 1.4.06}

Analysis of oxygen transport enhancement by functionalized magnetic nanoparticles (FMP) in bioprocesses

Filipe Ataíde*, Cristiana Azevedo, Joao J. Clemente, Antonio E. Cunha, Filomena Freitas, Maria A.M. Reis, Ana C.A. Roque, Rui Oliveira

\section{FCT-UNL, Caparica, Portugal}

The central goal of this study was to develop functionalized magnetic nanoparticles (FMP) to enhance oxygen transport in bioprocesses. FMP were designed to possess a magnetic core and a coating suitable to confer colloidal stability to the particles in water dispersions. Previous studies have shown that FMP are able to increase the oxygen mass transfer coefficient by 6 -fold in Escherichia coli cultures.

Different magnetic nanoparticles with different coatings and sizes were pre-screened in shake flasks against cellular aggregation, which needs to be prevented in cultivation conditions. In particular, FMP with silica and oleic acid coating were evaluated since these particles are inexpensive and are currently available in the market.

A glass 0.5-1 reactor was custom manufactured for assessment of oxygen transport enhancement due to FMP. The reactor design, baffles and Rushton impeller are of standard dimensions, namely, $w B / T=1 / 10, D / T=1 / 3$. Mass transfer tests were carried out through the use of the sulphite oxidation method, applying iodometric back-titration.

For determination of kLa a catalyst concentration of $10^{-6} \mathrm{M}$ (under which there is no mass transfer enhancement by the chemical reaction) was used while for the determination of interfacial area a catalyst concentration of $10^{-4} \mathrm{M}$ was used. The parameters used for mass transfer runs with FMP were: 300-600 rpm for stirring speed, $0.5-2.0 \mathrm{vvm}$ for aeration, $0.8 \mathrm{M}$ of initial sodium sulfite concentration and $0-4 \%$ FMP mass fraction.

http://dx.doi.org/10.1016/j.nbt.2012.08.210

\section{Poster 1.4.07}

Establishing new microbial cell factories for sustainable bioprocesses

Mhairi Workman*, Philippe Holt, Xiaoying Liu

Center for Microbial Biotechnology, Department of Systems Biology, Technical University of Denmark, 2800 Kgs Lyngby, Denmark

The demands of modern society are increasing pressure on natural resources while creating the need for a wider range of products. There is an interest in developing bioprocesses to meet these demands, with conversion of a variety of waste materials providing the basis for a sustainable society. The application of biological catalysts which can convert a variety of substrates to an array of desirable products has been demonstrated in both ancient bioprocesses and modern industrial biotechnology. In recent times, focus has been on a limited number of "model" organisms which have been extensively exploited and developed. Systems biology approaches can be applied with these well studied strains, 
where considerable physiological data has been obtained, genome sequences are known and genetic tools have been developed.

With the necessity of considering a wider array of substrates and the need for new types of products, it may be interesting to look to less domesticated strains and towards more non-conventional hosts in the development of new bioprocesses. This approach demands thorough physiological characterization as well as establishment of tools for genetic engineering if new cell factories are to be exploited through application of systems biology tools. Here two potential cell factories for the conversion of glycerol are described: Pachysolen tannophilus and Yarrowia lipolytica. These organisms exhibit considerable potential; producing ethanol and 1,3-butanediol (P. tannophilus) and organic acids, lipids and polyols $(Y$. lipolytica). In addition to their product range the strains are also capable of converting carbon sources found in a range of sustainable feedstocks.

http://dx.doi.org/10.1016/j.nbt.2012.08.211

\section{Poster 1.4.08}

Growth characteristics determination for in vitro and pilot-scale growth of the potential probiotic, Enterococcus faecium to be used in fish aquaculturing

Haluk Hamamci, Ali Oğuz Büyükkileci, Nihal Destan Aytekin*

Middle East Technical University, Ankara, Turkey

The aquaculturing of marine and fresh water fish is one of the fastest growing sectors in the world and in Turkey. Rainbow trout (Oncorhynchus mykiss) has the highest share in aquaculturing in Turkey. Within the industry, especially after the antibiotic usage in true feed is phased throughout the world, the need for enhanced disease resistance, growth performance, feed efficiency has come to order. Probiotic usage is a proved alternative, not only for helping control of specific diseases, contributing to digestive systems and development of the immune systems, but also for performing antagonistic effect against fish pathogens by aiding the defensive barrier of gut microbiota. The primary application in aquaculturing has been to effect the composition of the aquatic medium.

In this study, optimum growth parameters for both batch growth of potential probiotic, Enterococcus faeicum and fed-batch growth of the microorganism were determined. In the batch studies, varying amounts of pepton, yeast extract and glucose were tried. Whey was evaluated as an alternative carbonhydrate source for decreasing product cost. The trials showed comparable growth maintenance up to an OD of 8 at $600 \mathrm{~nm}$.

The probiotic will be maintained in a form to be fed to aquacultured trouts in pilot scale and in bilateral fish farms. Also, the antagonistic effect of the microorganism against the pathogens; Vibrio anguillarium, Lactococcus garviae, Yersinia enterocolitica that are isolated from rainbow trout microbiota, has been investigated and according to pre-studies, Lactacoc is observed to be declined at least 10 folds.

http://dx.doi.org/10.1016/j.nbt.2012.08.212

\section{Poster 1.4.09}

Process optimization of antibiotic production by Actinoplanes friuliensis

A. Steinkämper ${ }^{1, *}$, A. Wolf ${ }^{2}$, R. Masuch ${ }^{2}$, J. Hofmann ${ }^{1,2}, \mathrm{~K}$. Mauch $^{3}$, J. Schmid ${ }^{3}$, D. Schwartz ${ }^{1}$, R. Biener ${ }^{1}$

${ }^{1}$ University of Applied Sciences Esslingen, Esslingen, Germany

${ }^{2}$ Micro-biolytics $\mathrm{GmbH}$, Esslingen, Germany

${ }^{3}$ Insilico Biotechnology, Stuttgart, Germany

Actinoplanes friuliensis is a rare actinomycete which produces the highly potent lipopeptide antibiotic friulimicin. This antibiotic is active against a broad range of multiresistant gram-positive bacteria such as methicillin-resistant Enterococcus spec. and Staphylococcus aureus (MRE, MRSA) strains [1].

In order to characterize the complex interactions of antibiotic metabolism in $A$. friuliensis, cultivations are carried out in a bioreactor under defined and controlled conditions. A chemically defined production medium, especially developed for $A$. friuliensis, is used. This defined medium is a prerequisite for the quantitative analysis of cell metabolism during the cultivations and is also necessary to apply a new developed middle infrared spectroscopy method (AquaSpec Technology, micro-biolytics GmbH, Esslingen). With this method, all known substrates and metabolites can be measured in one sample.

For friulimicin biosynthesis by $A$. friuliensis some amino acids are required as substrates. Ammonium is produced as a by-product of amino acid metabolism. It was shown to inhibit friulimicin biosynthesis. Therefore, fed-batch cultivation strategies are developed in order to avoid production of this by-product.

Data from cultivations are also used to develop a metabolic flux model (Insilico Biotechnology, Stuttgart) on the basis of genome data (Cebitec, Bielefeld).

The flux model, combined with data from cultivation and transcription analysis, should give hints for directed genetic modifications and optimization of process control strategies with the objective to redirect metabolic fluxes towards friulimicin production.

\section{Reference}

1. Aretz W, et al. J Antibiot (Tokyo) 2000;53:807-15.

http://dx.doi.org/10.1016/j.nbt.2012.08.213

Poster 1.4.10

Dynamics monitoring of industrial bioprocesses realized in scale-down simulators

V. Lyubenova ${ }^{1, *}$, S. Junne ${ }^{2}$, M. Ignatova ${ }^{1}$, P. Neubauer ${ }^{1,2}$

${ }^{1}$ Institute of System Engineering and Robotics, Bulgarian Academy of Sciences, Acad. G. Bontchev str. Bl. 2, PO Box 79, Sofia, Bulgaria

${ }^{2}$ Bioprocess Engineering, Department of Biotechnology, Technische Universität Berlin, Ackerstrasse 71-76 ACK24, Germany

Unwanted substrate gradient in industrial-scale bioreactors predetermines cell's growth in oscillating conditions. For experimental 